\title{
Antimicrobial properties of two naphthopyrandione derivatives with cycloalkanespirohydantoins towards some phytopathogenic and beneficial microorganisms
}

\section{Marin Marinov, Mladen Naydenov, Rumyana Prodanova}

\section{Agricultural University, Plovdiv, Bulgaria}

Keywords:

Naphthopyrandione

Cycloalkanespiro-

hydantoins

Antimicrobial

Phytopathogenic

Microorganism

Article history:

Received 14.06.2018

Received in revised

form 22.09.2018

Accepted 27.12.2018

\section{Corresponding}

author:

Marin Marinov

E-mail:

m_n_marinov@ abv. $\overline{b g}$

DOI: $10.24263 / 2304-$ 974X-2018-7-4-15

\section{Abstract}

Introduction. Antimicrobial properties of two naphthopyrandione derivatives with cycloalkanespirohydantoins towards some phytopathogenic and beneficial microorganisms are investigated and presented in this work.

Materials and methods. The title compounds are obtained following a known procedure. The agar well diffusion test is applied to determine the antimicrobial activities of the synthesized products on bacteria and fungi. The initial cycloalkanespirohydantoins are prepared via the Bucherer-Lieb method. The starting compounds used in the studies, namely 6bromo-1H,3H-naphtho[1,8-cd]pyran-1,3-dione, cycloalkanespirohydantoins, naphthopyrandione derivatives with cycloalkanespirohydantoins, namely

3-(1,3-dioxo-1H,3H-naphtho[1,8-cd]pyran-6-yl)-1,3-diazaspiro [4.4]-nonane-2,4-dione and

3-(1,3-dioxo-1H,3H-naphtho[1,8-cd]pyran-6-yl)-1,3diazaspiro[4.5]decane-2,4-dione, are synthesized according to the methods described in the literature.

Results and discussion. The antimicrobial activity of the parent compounds and the final products is investigated against the fungi Fusarium oxysporum and Trichoderma asperellum T6, the Gram-positive bacterium Bacillus amyloliquefaciens 2/7 A and the Gram-negative bacterium Xanthomonas vesicatoria. All substances (except the initial spirohydantoins) show activity to the microorganisms studied. With regard to the test fungi, more susceptible are those of phytopathogenic species (Fusarium oxysporum). The effect is different in the case of bio-control agent (Trichoderma asperellum T6). In addition to being weaker, over time, the fungus overcomes the inhibitory effect as its growth covers inhibition zones already formed. The 3-(1,3-dioxo- $1 \mathrm{H}, 3 \mathrm{H}$ naphtho[1,8-cd] pyran-6-yl)-1,3-diazaspiro[4.5]decane-2,4-dione shows the highest activity against phytopathogenic microorganisms while having a relatively lower effect against Trichoderma asperellum T6.

Conclusions. The 6-bromo- $1 H, 3 H$-naphtho[1,8-cd]pyran1,3-dione, 3-(1,3-dioxo-1H,3H-naphtho[1,8-cd]pyran-6-yl)-1,3diazaspiro[4.4]nonane-2,4-dione and 3-(1,3-dioxo- $1 \mathrm{H}, 3 \mathrm{H}$ naphtho[1,8-cd]pyran-6-yl)-1,3-diazaspiro[4.5]decane-2,4-dione possessed the highest biological activity to all of the tested microorganisms. 


\section{Introduction}

The hydantoins (imidazolidinediones) are substances with a broad spectrum of biological activity. Different derivatives of such compounds are known as antimicrobial agents [1-34].

The antimicrobial activity of various spirohydantoins and their derivatives has been investigated and reported in previous studies of ours. Some of the products tested for the presence of such type of activity are shown in figure 1 .<smiles>O=C1NC(=O)C2(CCCC2)N1</smiles>

a<smiles>NN1C(=O)NC2(C1=O)c1ccccc1-c1ccccc12</smiles>

d<smiles>S=C1NC(=S)C2(CCCC2)N1</smiles>

b<smiles>[NH3+]C1(C(=O)[O-])CCCC1</smiles>

c

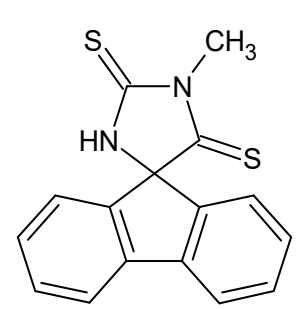

$\mathbf{e}$<smiles>CCn1cc(C(=O)NN2C(=O)NC3(CCCCC3)C2=O)c(=O)c2ccc(C)nc21</smiles>

f

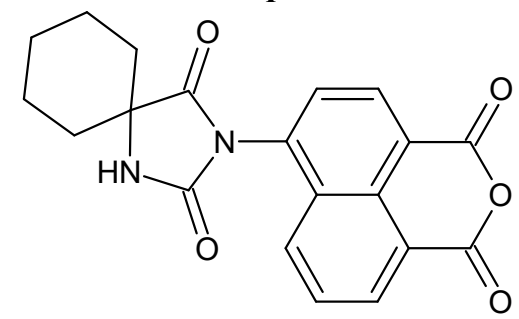

h

Figure 1. Some biologically active spirohydantoins and their derivatives

The cyclopentanespiro-5-hydantoin /1,3-diazaspiro[4.4]nonane-2,4-dione/ (figure 1a), cyclopentanespiro-5-(2,4-dithiohydantoin) /1,3-diazaspiro[4.4]nonane-2,4-dithione/ (figure 1b) and 1-aminocyclopentane-1-carboxylic acid (figure 1c) have shown strong fungicidal activity against Blumeria graminis f. sp. tritici (wheat powdery mildew) [35]. Other compounds with pronounced fungicidal properties are

3-(1,3-dioxo-1H,3H-naphtho[1,8-cd]pyran-6-yl)-1,3-diazaspiro[4-4]nonane-2,4-dione (Figure $1 \mathrm{~g})$ and

3-(1,3-dioxo-1H,3H-naphtho[1,8-cd]pyran-6-yl)-1,3-diazaspiro[4.5]decane-2,4-dione (figure $1 \mathrm{~h}$ ).

Both products completely inhibited the germination of the Monilia fructigena (brown rot) conidia [36]. With regard to Plasmopara viticola (grapevine downy mildew), only the cyclopentyl derivative (figure 1g) was found to be effective [37]. The 3-amino-9'- 
fluorenespiro-5-hydantoin /3'-aminospiro[fluorene-9,5'-imidazolidine]-2',4'-dione/ (figure 1d) exhibited a distinct antibacterial activity against the Gram-negative bacterium Escherichia coli [38]. In contrast to the example above, it was found out that the 3-methyl(9'-fluorene)-spiro-5-(2,4-dithiohydantoin) /3'-methylspiro[fluorene-9,5'-imidazolidine]2',4'-dithione/ (figure 1e) showed antibacterial effect towards Gram-positive bacteria (Staphylococcus aureus and Bacillus subtilis) [39]. The N-(2,4-dioxo-1,3diazaspiro[4.5]decan-3-yl)-1-ethyl-7-methyl-4-oxo-1,4-dihydro-1,8-naphthyridine-3-

carboxamide (figure 1f) possessed a certain antibacterial activity against Gram-positive and Gram-negative bacteria [40].

The current work is a continuation of the biological activity research of 3-(1,3-dioxo1H,3H-naphtho[1,8-cd]pyran-6-yl)-1,3-diazaspiro[4.4]nonane-2,4-dione (figure 1g) and 3(1,3-dioxo-1 $H, 3 H$-naphtho[1,8-cd]pyran-6-yl)-1,3-diazaspiro[4.5] decane-2,4-dione (figure 1h). Herein, we present a study of the antimicrobial activity of both compounds against bacterial and fungal cultures of phytopathogenic and beneficial microorganisms.

\section{Materials and methods}

\section{Synthetic compounds}

All chemicals used for the synthesis were purchased from Merck and Sigma-Aldrich. The melting points were determined with a SMP-10 digital melting point apparatus. The elemental analysis data were obtained with an automatic analyzer Carlo Erba 1106. The purity of the compounds was checked by thin layer chromatography on Kieselgel $60 \mathrm{~F}_{254}, 0.2$ mm Merck plates, eluent systems (vol. ratio): benzene : ethanol $=5: 1$, ethyl acetate : petroleum ether $=1: 2$ and $n$-butanol $:$ acetic acid $:$ water $=3: 1: 1$. The IR spectra were registered in $\mathrm{KBr}$ pellets on a VERTEX $70 \mathrm{FT}-\mathrm{IR}$ spectrometer (Bruker Optics) from 4000 $\mathrm{cm}^{-1}$ to $400 \mathrm{~cm}^{-1}$ at resolution $2 \mathrm{~cm}^{-1}$ with 25 scans. The NMR spectra were taken on a Bruker DRX-250 spectrometer, operating at 250.13 and $62.90 \mathrm{MHz}$ for ${ }^{1} \mathrm{H}$ and ${ }^{13} \mathrm{C}$, respectively, using the standard Bruker software. The chemical shifts were referenced to tetramethylsilane (TMS). The measurements in DMSO- $d_{6}$ solutions were carried out at ambient temperature $(300 \mathrm{~K})$. Typical conditions for ${ }^{1} \mathrm{H}$ NMR spectra were: pulse width $30^{\circ}$, $1 \mathrm{~s}$ relaxation delay, $16 \mathrm{~K}$ time domain points, zero-filled to $64 \mathrm{~K}$, hard pulse with $90^{\circ}$ pulse width of $11.8 \mu \mathrm{s} ;{ }^{13} \mathrm{C}$ NMR spectra: pulse width $30^{\circ}, 1 \mathrm{~s}$ relaxation delay, $16 \mathrm{~K}$ time domain points, zero-filled to $32 \mathrm{~K}$, hard pulse with $90^{\circ}$ pulse width of $6.4 \mu$ s at a power level of $3 \mathrm{~dB}$ below the maximum output.

\section{Microorganisms}

Bacterial and fungal cultures of phytopathogenic and beneficial microorganisms were used to study the biological activity of the test substances. Fungi used were the phytopathogenic Fusarium oxysporum and the bio-control agent Trichoderma asperellum T6. The Gram-positive Bacillus amyloliquefaciens $2 / 7 \mathrm{~A}$, having the ability to stimulate plant growth and to restrict the development of fungal phytopathogens and plant pathogenic and the Gram-negative Xanthomonas vesicatoria were used as bacterial test cultures. The microorganisms used in the study were from the collection of the Laboratory of microbial technologies except Xanthomonas vesicatoria, kindly provided by Dr. Katia Vasileva from Maritsa Vegetable Crops Research Institute, Plovdiv. 


\section{Biological assay}

The agar well diffusion method was applied to determine the antimicrobial activities of compounds 1a, 1b, 2, 3a and 3b on the bacteria and fungi [41-43]. The incubations were done on tryptic soy agar (TSA Biolife 4021552) for the bacterial isolates and potato dextrose agar (Merck 1.10130.0500) for the fungi. The agar plate surface was inoculated by spreading 100 $\mu \mathrm{l}$ of the microbial inoculum, adjusted to yield approximately $1.0 \times 10^{8}$ cfu per ml with sterile water. Then, a hole with a diameter of $10 \mathrm{~mm}$ was punched aseptically with a sterile cork borer and a volume of $50 \mu \mathrm{l}$ of the dimethylsulfoxide (DMSO) solution of the synthesized compounds in concentration of $20 \mathrm{mg} / \mathrm{ml}$ was introduced into the well. The agar plates were incubated in thermostat at $28^{\circ} \mathrm{C}$ for all microorganisms. The inhibition zones were recorded at 48 and $96 \mathrm{~h}$. The inhibition zones were analyzed using Digimizer ${ }^{2} 4.6 .1$, image analysis software.

\section{Results and discussion}

The synthesis of the title naphthopyrandione derivatives with cycloalkanespirohydantoins was carried out according to Figure 1.

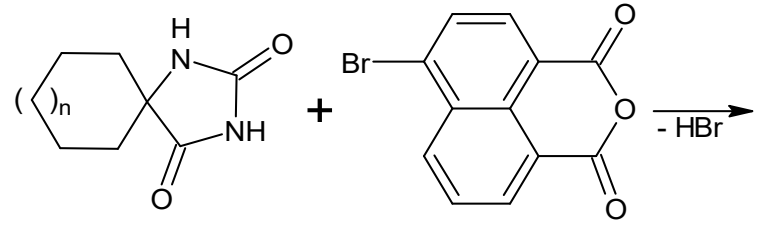

1
2

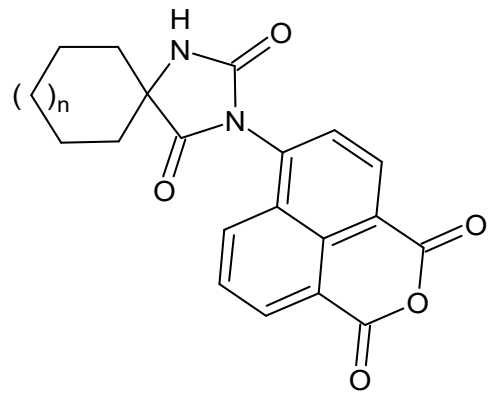

3

a) $n=0 ;$ b) $n=1$

Figure 1. Synthesis of naphthopyrandione derivatives with cycloalkanespirohydantoins [36]

The cyclopentanespiro-5-hydantoin (1a) and cyclohexanespiro-5-hydantoin (1b) were prepared via the Bucherer-Lieb method [44]. The synthesis was performed by the reaction of cyclopentanone and cyclohexanone with sodium cyanide, ammonium carbonate and ethanol.

The 4-bromo-1,8-naphthalic anhydride (2) was obtained by the bromination of 1,8naphthalic anhydride $/ 1 H, 3 H$-naphtho[1,8-cd]pyran-1,3-dione/ in accordance with Grayshan et al. [45].

The interaction of cycloalkanespirohydantoins (1a and 1b) with 4-bromo-1,8-naphthalic anhydride (2) led to 3-(1,3-dioxo-1H,3H-naphtho[1,8-cd]pyran-6-yl)-1,3diazaspiro[4.4]nonane-2,4-dione (3a) and 3-(1,3-dioxo-1H,3H-naphtho[1,8-cd]pyran-6-yl)1,3-diazaspiro[4.5]decane-2,4-dione (3b) formation [36].

The compounds cited above (see table 1) were characterized by physicochemical parameters, elemental analysis, IR and NMR spectral data. The results obtained from these analyses match the literature data [36, 45-48]. 
Table 1

Compounds used for the biological tests

\begin{tabular}{|c|c|c|c|}
\hline № & Structure & $\begin{array}{c}\text { Name / } \\
\text { IUPAC* }{ }^{*} \text { systematic name }\end{array}$ & $\begin{array}{l}\text { Synthesis } \\
\text { procedure }\end{array}$ \\
\hline $1 \mathrm{a}$ & & $\begin{array}{c}\text { Cyclopentanespiro-5- } \\
\text { hydantoin } \\
\text { /1,3-Diazaspiro[4.4]nonane- } \\
\text { 2,4-dione/ }\end{array}$ & [44] \\
\hline $1 b$ & & $\begin{array}{c}\text { Cyclohexanespiro-5- } \\
\text { hydantoin } \\
\text { /1,3-Diazaspiro[4.5]decane- } \\
\text { 2,4-dione/ }\end{array}$ & [44] \\
\hline 2 & & $\begin{array}{c}\text { 4-Bromo-1,8-naphthalic } \\
\text { anhydride } \\
\text { /6-Bromo- } 1 H, 3 H \text { - } \\
\text { naphtho[1,8-cd]pyran-1,3- } \\
\text { dione/ }\end{array}$ & [45] \\
\hline $3 \mathbf{a}$ & & $\begin{array}{c}\text { 3-(1,3-Dioxo- } 1 H, 3 H \text { - } \\
\text { naphtho[1,8-cd]pyran-6-yl)- } \\
\text { 1,3-diazaspiro[4.4]nonane- } \\
\text { 2,4-dione }\end{array}$ & [36] \\
\hline $3 \mathbf{b}$ & & $\begin{array}{c}\text { 3-(1,3-Dioxo- } 1 \mathrm{H,3H} \text { - } \\
\text { naphtho[1,8-cd]pyran-6-yl)- } \\
\text { 1,3-diazaspiro[4.5]decane- } \\
\text { 2,4-dione }\end{array}$ & [36] \\
\hline
\end{tabular}

* International Union of Pure and Applied Chemistry

The research of synthesized substances, that are active against phytopathogens, requires verification of their action against microorganisms, harmful to plants, as well as useful microorganisms in combination with which they could be used.

In this preliminary study, bacteria and fungal strains important for growing quality agricultural produce are selected. Two phytopathogenic microorganisms, one fungus and one bacterium, have been selected. The other two microorganisms tested were beneficial bacteria and fungi that have the ability to control plant diseases and stimulate plant growth. This leads to an increase in the quantity and quality of the agricultural products.

Xanthomonas vesicatoria is a Gram-negative, aerobic, rod-shaped bacterium that causes leaf and fruit spots on peppers and tomatoes $[49,50]$. X. vesicatoria occurs widely in tomatoand Capsicum-growing areas in different parts of the world and bacterial spot is common and 
serious disease. Bacterial spot lesions can be observed on leaves, stems and fruit and occurs during all stages of plant growth. In favorable weather conditions, spots can coalesce and cause large areas of chlorosis. While fruit lesions are often only superficial, they reduce product quality in terms of fresh consumption and processing.

Fusarium oxysporum is a soilborne pathogenic fungus of worldwide importance [51]. The pathogen enters the plant through the roots and is then spread throughout the plant by the vascular system. This fungus can cause severe damages to many types of vegetables, flowers and field crops.

Fungi from the genus Trichoderma and bacteria from the genus Bacillus have been widely used in the agriculture as biocontrol agents. They possess a mycoparasitic capacity and ability to improve plant health and protection against phytopathogens, as well as to increase tolerance to biotic and abiotic stresses [52-54].

The antimicrobial activity of the parent compounds and the final products was investigated against the fungi Fusarium oxysporum and Trichoderma asperellum T6, the Gram-positive bacterium Bacillus amyloliquefaciens 2/7 A and the Gram-negative bacterium Xanthomonas vesicatoria (see the "Materials and methods" part). The results of the conducted tests are presented in figures 2-4.

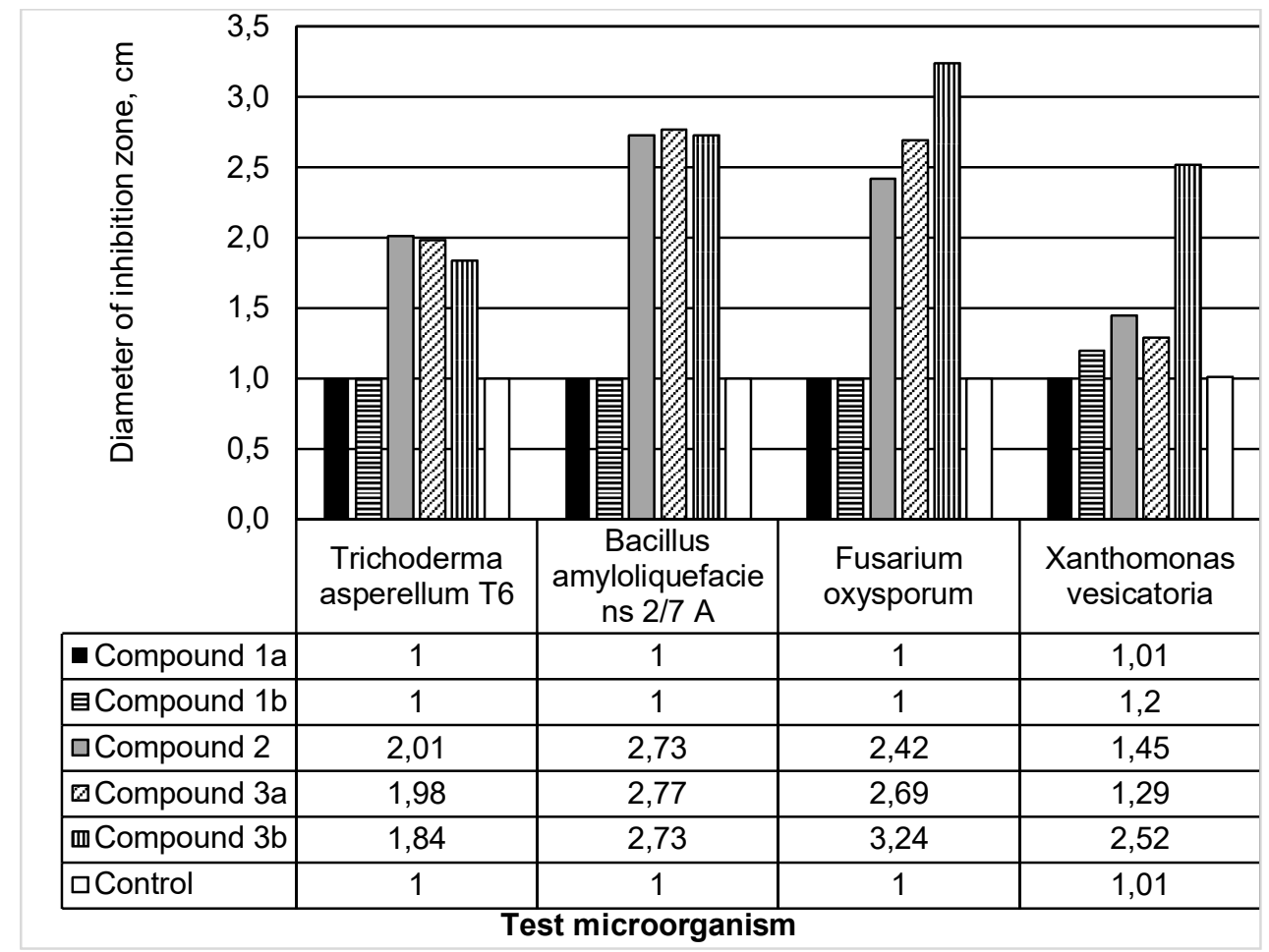

Figure 2. Inhibition zones $(\mathrm{cm})$ of the test substances

All substances (except the initial spirohydantoins 1a and 1b) show activity towards all studied microorganisms. With regard to the test fungi, more susceptible are those of phytopathogenic species (Fusarium oxysporum). 


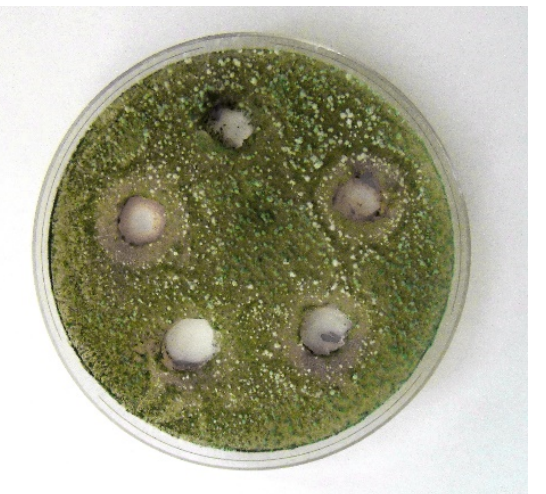

Figure 3. Overcomed inhibitory effect by Trichoderma asperellum T6

The effect is different in the case of biocontrol agent (Trichoderma asperellum T6, Figure 3). In addition to being weaker, over time, the fungus overcomes the inhibitory effect as its growth covers inhibition zones already formed.

With respect to the test substances, the biological activity of compounds $2,3 \mathrm{a}$ and $3 \mathrm{~b}$ is the highest of all tested microorganisms. Compound $3 \mathrm{~b}$ shows the highest activity against phytopathogenic microorganisms while having a relatively lower effect against Trichoderma asperellum T6. The remaining substances differ in their activity against various microorganisms, however, their cumulative activities to all microorganisms are approximately the same and

do not differ to the control (Figure 4).



Figure 4. Cumulative activity of the compounds against test microorganisms

\section{Conclusions}

When comparing the activity of the original and the synthesized substances it is obvious that the initial materials practically do not exhibit biological activity to the test microorganisms.

The synthesized substances exhibit biological activity against all tested microorganisms. As such, these are of interest for further research. Compound $\mathbf{3 b}$ depicts the highest activity, which is the only substance that has a significant activity against Xanthomonas vesicatoria.

Another important observation is that the activity exerted on the fungal bio-control agent Trichoderma asperellum T6 is expressed in temporary growth retention, which is then overcome by the fungus. 
The latter can be used in the joint application of test substances together with fungal biocontrol agents of the genus Trichoderma for the control of plant diseases in the production of safe plant produce for consumption and future processing.

Acknowledgements. Financial support by the Agricultural University Plovdiv, Bulgaria (Contract 06-18) is gratefully acknowledged. We are also grateful to Prof. N. Stoyanov, Razgrad, for stimulating discussions.

\section{References}

1. Wolf C. N., Ligett W. B. (1960), Fungicidal composition of a hydantoin selected from the group consisting of 5,5 polymethylene and 5,5 diaryl, and 5,5 aryl, alkyl hydanton, United States Patent № 2,920,997.

2. Cremlyn R. J. C.-D., Elias R. S., Geoghegan M. J. A., Braunholtz J. T. (1965), NTrichloromethylthiohydantoins, United States Patent № 3,177,224.

3. Fujinami A., Ozaki T., Horiuchi F., Yamamoto S., Akiba K., Tanaka K., Ooba S., Ooishi T., Nodera K., Kameda N. (1972), 3-(3',5'-Dihalogenophenyl) imidazolidine-2,4-dione derivatives, United States Patent № 3,668,217.

4. Sauli M. (1973), Substituted 3-phenyl hydantoins useful as fungicides, United States Patent № $3,755,350$.

5. Singer M. (1974), Herbicidal and/or fungicidal 5-poly-haloethylimino- and 5polyhalovinylimino-2,4-imidazolidinedione, United States Patent № 3,822, 282.

6. Hubele A. (1976), Imidazolidine-2,4-dione derivatives and their use as pesticides, United States Patent № 3,960,883.

7. Enders E., Frohberger P. -E. (1977), Combating fungi with 1-aryl-5-alkylidene-2,4-dioxo imidazolidines, United States Patent № 4,053,620.

8. Sonntag N. O. V. (1978), Hydantoin derivatives and broad spectrum bactericidal/ fungicidal compositions thereof, United States Patent № 4,073,924.

9. Shull S. E., Bennett E. O. (1979), Antimicrobal hydanton derivative compositions and method of use, United States Patent № 4,172,140.

10. Rentzea C., Pommer E.-H., Mappes C. J., Zeeh B. (1980), 1,3-Bis-(trihalomethylsulfenyl)imidazoline-2,4-diones, United States Patent № 4,198,423.

11. Zaidi S. M. M., Satsangi R. K., Nasir P., Agarwal R., Tiwari S.S. (1980), New anti-mycobacterial hydantoins, Pharmazie, 35, 755-756.

12. Asao S., Yamamoto S., Hisada Y., Nakayama Y., Takayama C. (1980), Imidazolidinedione compounds, and their production and use, United States Patent № 4,237,22.

13. Hubele A. (1982), Imidazolidine-2,4-dione derivatives, process for their preparation and their microbicidal application, European Patent Application № 0043348A1.

14. Takayama C., Fujinami A., Kirino O., Kato T. (1983), Quantitative structure-activity relationships of antifungal 1-acyl-3-(3,5-dichlorophenyl)-2,4-imidazolidinediones, Journal of Pesticide Science, 8(2), pp. 193-198.

15. Takayama C., Imajo H., Kirino O., Miyashita J., Sasaki S. (1983), Steric effect of acyl moiety substituents on the antifungal activity of 1-acyl-3-(3,5-dichlorophenyl)-2,4-imidazolidinediones, Journal of Pesticide Science, 8(4), pp. 583-586.

16. Moore J. E. (1986), 1-Substituted-3-polyhaloalkylthio hydanton fungicides, United States Patent № 4,602,029.

17. Takayama C., Kirino O., Hisada Y., Fujinami A. (1987), Quantitative structure-activity relationships for antifungal 3-(3,5-dichlorophenyl)-2,4-imidazolidinediones, Agricultural and Biological Chemistry, 51(6), pp. 1547-1552.

18. Chan H.-F. (1988), Substituted 2,4-imidazolidinediones and fungicidal compositions, United States Patent № 4,753,957. 
19. Mohamed A. M., El-Sharief A. M., Ammar Y. A., Aly M. M. (1989), Synthesis and antimicrobial activity of some new 2,5-imidazolidinediones, Pharmazie, 44, 765-767.

20. Schoenberg T. G. (1991), Antimicrobial preservative system and method comprising a formaldehyde substituted hydanton, United States Patent № 5,037,843.

21. Goes A. J., De Lima M. C., Galdino S. L., Pitta I. R., Luu-Duc C. (1991), Synthesis and antimicrobial activity of substituted, fluorobenzyl benzylidenethiazolidinediones and imidazolidinediones, Journal de Pharmacie de Belgique, 46, pp. 236-240.

22. Lima M. C., Costa D. L., Goes A. J., Galdino S. L., Pitta I. R., Luu-Duc C. (1992), Synthesis and antimicrobial activity of chlorobenzyl benzylidene imidazolidinedione derivatives and substituted thiazolidinediones, Pharmazie, 47, pp. 182-184.

23. Marton J., Enisz J., Hosztafi S., Timar T. (1993), Preparation and fungicidal activity of 5substituted hydantoins and their 2-thio analogs, Journal of Agricultural and Food Chemistry, 41(1), pp. 148-152.

24. Hsu A. C. T., Shaber S. H., Michelotti E. L. (1994), N-Iodopropargyl hydantoin compounds, compositions, preparation, and use as antimicrobial agents, United States Patent № 5,346,913.

25. Albuquerque J. F. C., Rocha Filho J. A., Brandao S. S. F., Lima M. C. A., Ximenes E. A., Galdino S. L., Pitta I. R., Chantegrel J., Perrissin M., Luu-Duc C. (1999), Synthesis and antimicrobial activity of substituted imidazolidinediones and thioxoimidazolidinones, Il Farmaco, 54, pp. 77 82.

26. Lin J., Winkelman C., Worley S. D., Broughton R. M., Williams J. F. (2001), Antimicrobial treatment of nylon, Journal of Applied Polymer Science, 81, pp. 943-947.

27. Szymańska E., Kieć-Kononowicz K., Białecka A., Kasprowicz A. (2002), Antimicrobial activity of 5-arylidene aromatic derivatives of hydantoin. Part 2, Il Farmaco, 57, pp. 39-44.

28. Kaziska A. J., Czuczak M. F., Lemke D. W. (2004), Sustained release antimicrobial composition including a partially halogenated hydanton and a colorant, United States Patent Application Publication № US 2004/0043914A1.

29. Barnes K., Liang J., Wu R., Worley S. D., Lee J., Broughton R. M., Huang T. S. (2006), Synthesis and antimicrobial applications of 5,5'-ethylenebis[5-methyl-3-(3-triethoxysilylpropyl)hydantoin], Biomaterials, 27, pp. 4825-4830.

30. Chen Z., Sun Y. (2006), N-Halamine-based antimicrobial additives for polymers: preparation, characterization, and antimicrobial activity, Industrial \& Engineering Chemistry Research, 45, pp. 2634-2640.

31. Abdel-Aty A. H. (2009), Pesticidal effects of some imidazolidine and oxazolone derivatives, World Journal of Agricultural Sciences, 5(1), pp. 105-113.

32. Mandal A., Krishnan R. S. G., Thennarasu S., Panigrahi S., Mandal A. B. (2010), Twodimensional surface properties of an antimicrobial hydantoin at the air-water interface: An experimental and theoretical study, Colloids and Surfaces B: Biointerfaces, 79, pp. 136-141.

33. Kocer H. B., Worley S. D., Broughton R. M., Huang T. S. (2011), A novel N-halamine acrylamide monomer and its copolymers for antimicrobial coatings, Reactive \& Functional Polymers, 71, pp. $561-568$.

34. Tan L., Maji S., Mattheis C., Chen Y., Agarwal S. (2012), Antimicrobial hydantoin-grafted poly(e-caprolactone) by ring-opening polymerization and click chemistry, Macromolecular Bioscience, 12(12), pp. 1721-1730.

35. Marinov M., Ganchev D., Nikolov A., Marinova P., Krustev S., Madzharova V., Stoyanov N. (2013), In vitro fungicidal activity of cyclopentanespiro-5-hydantoin and its derivatives towards Blumeria graminis f. sp. tritici, Agricultural Sciences, 12, pp. 97-101.

36. Marinov, M., Ganchev D., Frenkeva M., Prodanova R., Penchev P. (2018), New naphthopyrandione derivatives with cycloalkanespirohydantoins: synthesis, characterization and fungicidal activity towards Monilia fructigena, Agricultural University - Plovdiv, Scientific Works, LXI(2), pp. 209-215.

37. Marinov M., Ganchev D., Prodanova R. (2018), Fungicidal activity of some spirohydantoins and their derivatives towards Plasmopara viticola, Journal Scientific and Applied Research, 13, pp. $58-64$. 
38. Marinova P., Marinov M., Feodorova Y., Kazakova M., Georgiev D., Lekova V., Penchev P., Stoyanov N. (2014), Synthesis, cytotoxicity and antibacterial activity of 3-amino-9'fluorenespiro-5-hydantoin, Comptes rendus de l'Académie bulgare des Sciences, 67(4), pp. 513518.

39. Marinova P., Marinov M., Feodorova Y., Kazakova M., Slavchev A., Blazheva D., Sarafian V., Nikolova I., Stoyanov N. (2014), Synthesis, characterization, in vitro antiproliferative and antimicrobial study of 3-methyl-(9'-fluorene)-spiro-5-(2,4-dithiohydantoin), Science \& Technologies, IV(1), pp. 112-117.

40. Marinov M., Kostova I., Naydenova E., Prodanova R., Marinova P., Penchev P., Stoyanov N. (2015), Synthesis and antimicrobial activity of new 3-substituted cyclohexanespiro-5-hydantoin derivatives, University of Ruse “Angel Kanchev" Proceedings, 54(10.2), pp. 62-67.

41. Magaldi S., Mata-Essayag S., Hartung de Capriles C., Perez C., Colella M. T., Olaizola C., Ontiveros Y. (2004), Well diffusion for antifungal susceptibility testing, International Journal of Infectious Diseases, 8(1), pp. 39-45.

42. Valgas C., de Souza S. M., Smânia E. F. A., Smânia Jr. A. (2007), Screening methods to determine antibacterial activity of natural products, Brazilian Journal of Microbiology, 38, pp. 369-380.

43. Balouiri M., Sadiki M., Ibnsouda S. K. (2016), Methods for in vitro evaluating antimicrobial activity: A review, Journal of Pharmaceutical Analysis, 6, pp. 71-79.

44. Bucherer H. T., Lieb V. A. (1934), Über die Bildung substituierter hydantoine aus aldehyden und ketonen. Synthese von hydantoinen, Journal für Praktische Chemie, 141, pp. 5-43.

45. Grayshan P. H., Kadhim A. M., Peters A. T. (1974), Heterocyclic derivatives of naphthalene-1,8dicarboxylic anhydride. Part III. Benzo[k,l] thioxanthene-3,4-dicarboximides, Journal of Heterocyclic Chemistry, 11, pp. 33-38.

46. Enchev V., Stoyanov N., Mateva V., Popova J., Kashchieva M., Aleksiev B., Mitewa M. (1999), Copper(II) complexes of spirohydantoins. Synthesis, quantum-chemical, and spectroscopic study, Structural Chemistry, 10(5), pp. 381-385.

47. Naydenova E., Pencheva N., Popova J., Stoyanov N., Lazarova M., Aleksiev B. (2002), Aminoderivatives of cycloalkanespirohydantoins: synthesis and biological activity, Il Farmaco, 57, pp. 189-194.

48. Naydenova E. D., Todorov P. T., Troev K. D. (2010), Synthesis and characterization of novel cycloalkanespiro-5-hydantoin phosphonic acids, Phosphorus, Sulfur, and Silicon, 185, pp. 13151320 .

49. Jones J. B., Bouzar H., Stall R. E., Almira E. C., Roberts P. D., Bowen B. W., Sudberry J., Strickler P. M., Chun J. (2000), Systematic analysis of xanthomonads (Xanthomonas spp.) associated with pepper and tomato lesions, International Journal of Systematic and Evolutionary Microbiology, 50, pp. 1211-1219.

50. Potnis N., Timilsina S., Strayer A., Shantharaj D., Barak J. D., Paret M. L., Vallad G. E., Jones J. B. (2015), Bacterial spot of tomato and pepper: diverse Xanthomonas species with a wide variety of virulence factors posing a worldwide challenge, Molecular Plant Pathology, 16(9), pp. $907-$ 920.

51. Michielse C. B., Rep M. (2009), Pathogen profile update: Fusarium oxysporum, Molecular Plant Pathology, 10(3), pp. 311-324.

52. Guzmán-Guzmán P., Porras-Troncoso M. D., Olmedo-Monfil V., Herrera-Estrella A. (2018), Trichoderma species: versatile plant symbionts, Phytopathology, available at: https://doi.org/10.1094/PHYTO-07-18-0218-RVW.

53. Qiao J.-Q., Wu H.-J., Huo R., Gao X.-W., Borriss R. (2014), Stimulation of plant growth and biocontrol by Bacillus amyloliquefaciens subsp. plantarum FZB42 engineered for improved action, Chemical and Biological Technologies in Agriculture, available at: https://doi.org/10.1186/s40538-014-0012-2.

54. Borriss R. (2011), Use of plant-associated Bacillus strains as biofertilizers and biocontrol agents in agriculture. In: Maheshwari D. (eds) Bacteria in agrobiology: plant growth responses, Springer, Berlin, Heidelberg. 